\title{
Investigation on Instagram Android-based using Digital Forensics Research Workshop Framework
}

\author{
Satrio Pambayun \\ Department of Informatics \\ Universitas Ahmad Dahlan \\ Yogyakarta of Indonesia
}

\author{
Imam Riadi \\ Department of Information System \\ Universitas Ahmad Dahlan \\ Yogyakarta of Indonesia
}

\begin{abstract}
The development of social media especially the Instagram app is very rapid. Instagram users usually do activities at any time by using Instagram as a communication tool to share information using an Android smartphone. One of the problems that social media doesn't solve is cybercrime among Instagram users. The case can be examined to obtain digital evidence in the form of chats and pictures/photos on Android smartphones. The investigation in this study uses the Digital Forensics Research Workshop (DFRWS) method which provides several stages of identification, maintenance, collection, examination, analysis, presentation. The process of data acquisition using OXYGEN forensics generates data in the form of photos/images and conversational text on the Instagram messaging service, while the acquisition with JSON Viewer only results in conversational sessions only. From the resulting data will be used as evidence.
\end{abstract}

Keywords

Cybercrime, DFRWS, Instagram. Oxygen Forensics

\section{INTRODUCTION}

The rapid development of internet and smartphone technology is followed by a rise in social media users accessing smartphones, especially Android. One of the problems that goes unnoticed by social media is cybercrime that utilizes social media. For there is basically no evil that leaves no trace[1]. Instagram is a photo sharing service app that allows users to take photos and filter and then disseminate them on social networks. Instagram is one of the social media that is being widely used by smartphone users today. Many Instagram users aim to communicate through Instagram social media, one of which is to fulfill uploading photos or sending chats that they do to fellow Instagram users[2]. Social media such as Instagram became the most widely used place by people using smartphones with the seventh highest number of users in the world reaching 53 million in January. While the first rank is occupied by the United States with 110 million and the second place is Brazil with 58 million, below Indonesia there is India with 52 million, ranked as advanced as Turkey with 33 million users then there is Russia 29 million, Iran 23 million, Japan 22 million, Britain 21 million and Mexico with 20 million Instagram users. Instagram user developments can be seen in Figure 1.

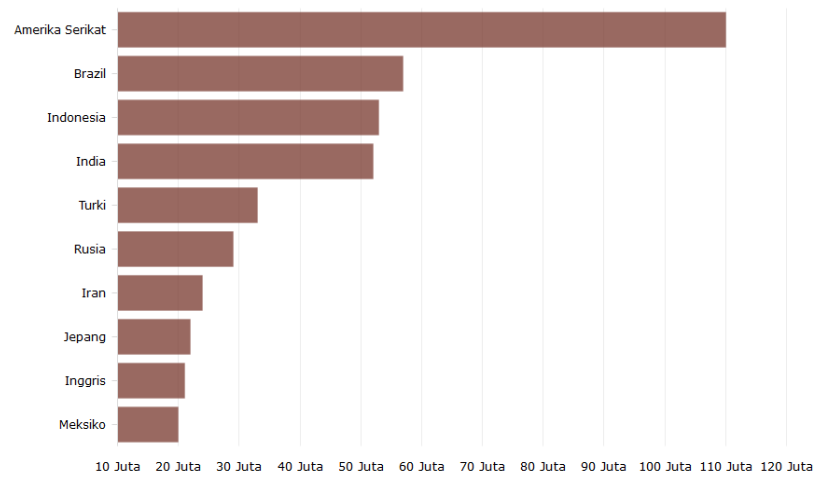

Figure 1. Instagram user in January 2019

The graph in figure 1 explaining the development of the number of Instagram users in January 2019 has reached 110 million people in the world as active users of Social Media Instagram Indonesia itself ranked third with 60 million instagram social media active users. Instagram social media officially announced the launch of an official feature called Instagram Messenger in 2013, this feature resembles Instant Messaging or syncat messages that exist on social media such as whatsapp and others. One thing Instagram social media lacks is the ability to keep conversations private with one person or a small group of fellow Instagram users, so this Instagram Messenger feature is a feature developed by Instagram social media to provide security to its users in conducting more private communication. Activities that can be done on Instagram Messenger feature are to communicate between fellow users in the form of conversational messages (Chat) and can also share images or photos with fellow Instagram users[3]. This can have a negative impact on the use of Instagram Messenger because it can provide the opportunity to use this feature to commit a crime that is most likely a cybercrime, especially cyberbullying crime, to solve the crime, hence the need for an analysis and forensic methods in order to help solve cyberbullying crimes that occur on Instagram social media[4].

\section{LITERATURE STUDY}

\subsubsection{Previous Research}

1. The first research entitled Spoofing Email Investigation with Metode Digital Research Workshop in 2016, conducted by Andri Lesmana Suryana, Reza El Akbar, Nur Widiyasono. The result of this research is that spoofing emails can be sent by utilizing web hosting services that provide services for email delivery using the PHP programming language and the next result is to know the difference will be clearly known when opening the detailed email header[5]. 
2. The second research is titled Digital Forensic Analysis Beetalk application for cybercrime handling in 2018, conducted by Muhammad Irwan Syahib, Imam Riadi, Rusydi Umar, If the smartphone is used as evidence in a criminal case, then a forensic mobile analysis action can be done so as to obtain digital evidence such as conversation history, images, documents, and videos[6].

3. A third study titled Acquisition of Google Drive Forensic Data on Android in 2018, conducted by Anton Yudhana, Rusydi Umar, Ahwan Ahmadi. The study successfully extracted Accounts, File extensions, images, zipped folders using the Oxygen Forensics app[7].

4. The fourth study titled Forensic Analysis and Comparison of Evidence of Social Media Application Facebook And Twitter On Android Smartphone conducted by Wisnu Ari Mukti, Siti Ummi Masruroh, Dewi Khairani in 2017. Forensic evidence of facebook found is account name, location data, phone number, date of birth, photo profile, cover photo, post in the form of text, post in the form of image, private message in the form of text and private message in the form of images. On Twitter, only account names, location data, photo profiles, cover photos, tweets and images were found[8].

5. The fifth research entitled Digital Forensic Analysis on Line Messenger Handling Cybercrime in 2017 conducted by Ammar Fauzan, Imam Riadi, Abdul Fadil. They analyzed the handling of cyberbullying cases by bringing up data on evidence of cyberbullying that occurred through the Line app[9].

\subsubsection{Digital Forensic}

Digital forensic is a field of science that learns about the investigation and recovery of data to obtain digital evidence as a means of evidence in court obtained from the investigation and analysis of digital computer data, mobile phones, CDR from operators and SIM cards[10]. Digital Forensics is an application of science and computer technology for the benefit of pro justice, which in this case is proving a crime - a high-tech crime or a scientific computer to be able to obtain digital evidence that can be used against offenders. Digital forensics has many fields, one of which is Mobile Forensics. Digital forensics is essentially being able to find digital evidence that can be stored on temporary computer storage, permanent storage, USB, CDs, network traffic, and more[11].

\subsubsection{Mobile Forensics}

Mobile forensics is an offshoot of digital forensics relating to the digital recovery of evidence or data from mobile devices under forensic sound conditions. Mobile devices are usually phrases referring to mobile phones, but can also be attributed to digital devices that have internal memory and communication capabilities. The use of mobile phones in crimes is that a lot of information taken from mobile devices can be useful in a variety of legal, administrative and investigative matters such as, Intellectual Property Theft, Corporate Fraud, Property Use, Divorce \& Family Law, Geographic location of controversy, Evidence of crime[12].

\subsubsection{Instagram}

Instagram is a social media that is used to send pictures/photos and bias also to have conversations/chats that can be used to facilitate communication between fellow Instagram social media users[13]. Instagram app can be seen in figure 2 .

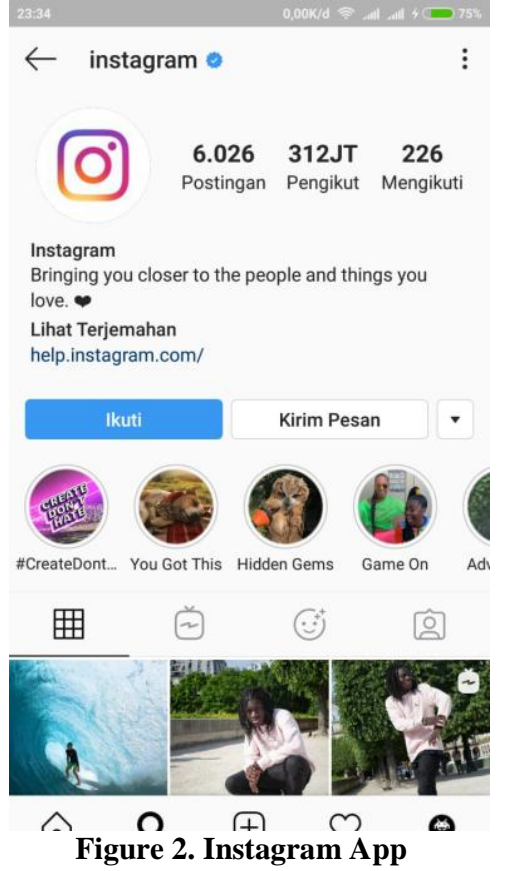

\subsubsection{Bully}

The word bullying comes from English, which is from the word bull which means bull who likes to duck around here. In Indonesian, etymologically the word bully means bully, the person who annoys the weak. Whereas terminology according to the definition of bullying is a desire to hurt. This desire is shown into action, causing a person to suffer. This action is performed directly by a stronger, irresponsible person or group, usually repetitive, and performed with pleasure. Bullying is a form of violent behavior where psychological or physical coercion occurs against a person or group of people who are weaker by a person or group of people. The perpetrator of bullying commonly called a bully can be a person, it can also be a group of people, and he or they perceive themselves to have the power to do anything against his victims. The victim also perceived herself as weak, helpless and always feeling bullied[14].

\subsubsection{Cyber Bullying}

Cyberbullying is where a child intimidates someone who is perceived to be weak. Intimidation occurs through technological means, through social media. Before cyberbullying, what happened first was an act of bullying. That is, actions that are then used to designate the aggressive behavior of a person or group to harm the victim. Acts of bullying can be physical, by slapping or injuring, then it can be verbal, this can usually be in a derogatory, mocking, and threatening manner. But this act of bullying through cyber media is more of a verbal act. It is a form of communication that communicators communicate to communion in a written or oral manner[15].

\subsubsection{Android}

Android is a subset of software for mobile devices that includes the operating system, middleware and core applications released by Google. Android is a mobile operating system that adopts the linux operating system, but has been modified. Android was taken over by Google in 2005 from Android,Inc. as part of a strategy to fill the mobile operating system market. Google takes over all Android work including team developing Android[16]. 


\subsubsection{DFRWS}

The Digital Forensic Research Workshop method includes the first six stages of identification. This stage to determine the needs that will be required for the investigation and search of digital evidence. The second stage of maintenance is to preserve the evidence and ensure the authenticity or integrity of the evidence so that the evidence is completely valid/ valid. The third stage, the collection stage, is the stage for the identification of gathering evidence sources that have the potential to be strong evidence. The fourth stage is the examination stage which is the stage to determine what will be analyzed or better known as data filtering, so that investigators can focus more on the next stage. The fifth stage is the analysis that is the stage to find and process the data including the data obtained from where, who is fertilize and how the data is generated. The final stage is the presentation stage which is the stage at which reporting and presenting the results of the analysis so that it can be understood by the public. [17]

\subsubsection{JSON}

Java Script Object Notation (JSON) is a data exchange format invented by Douglas Crockford in 2006 that has a smaller data size and faster processing time compared to pre-existing XML. Prior to the discovery of JSON, the existing web service used XML as a data exchange medium, which has become standard and commonly used by programmers, but now JSON can also be used as an alternative medium of data exchange in the web service[18]

\subsubsection{Oxygen Forensics}

Oxygen Forensic is a leading tool in the field of mobile forensics with the support of various types of mobile phones. Oxygen extracts most of the information in an efficient way. This tool has a good reporting system so that the examiner can read the detailed details of the evidence obtained[19].

\section{RESEARCH METHOD}

The research phase is a case simulation stage to try to implement data extraction in the Instagram app. The case simulation aims to test the extraction of data in the Instagram app used to search for conversational messages that are used as evidence. This stage of the study was conducted to find out the extent of the abuse committed within the Instagram app. The method used in this study is based on the Digital Forensics Research Workshop method[20]. DFRWS step can be seen in figure 3 .

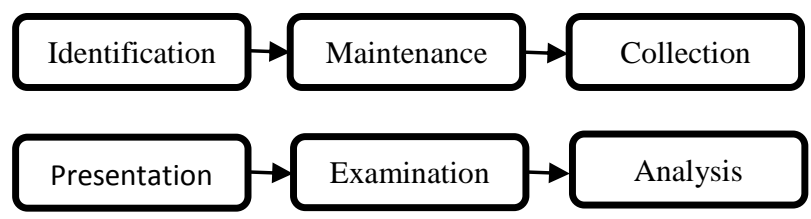

Figure 3. DFRWS Step

In figure 2 can be seen 6 stages of the Digital Forensic Research Workshop method

\subsubsection{Identification}

The identification process was first carried out on the evidence obtained. The evidence obtained is a smartphone with the BRAND ASUS Zenfone Max Pro M1 (ZB60KL) and os version Oreo 8.1.0 which is attached to the Instagram app with version 159.0.0.1.122. Evidence of instagram installed smartphones can be seen in Figure 4.

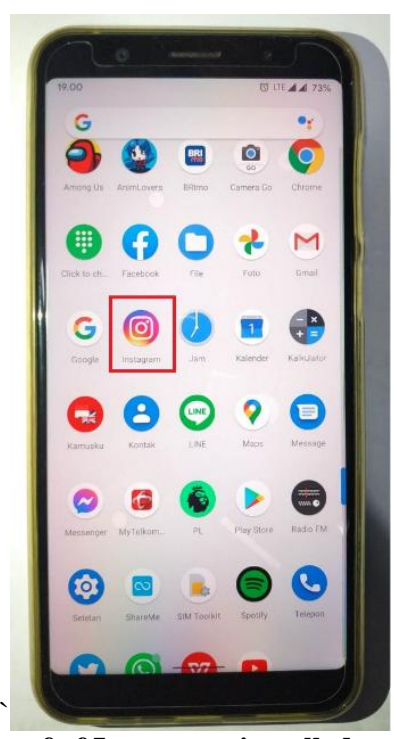

Figure 4. Proof of Instagram installed smartphone.

In addition to collecting and documenting, at this stage also carried out preparation and planning of how smartphones will be analyzed and using tools and some tools what is needed in carrying out the process. Identification using the Oxygen Forensic Tool can be seen in Figure 5.

\section{Zenfone Max Pro M1}
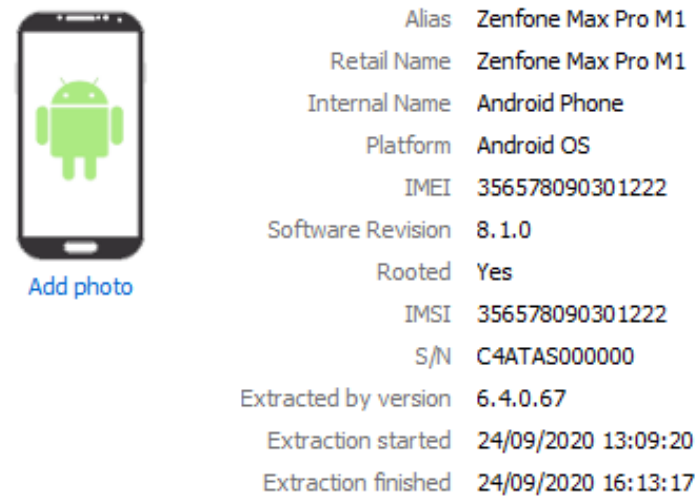

Figure 5. Identification using the Oxygen Forensic Tool

In figure 4 can be seen the specifications of the smartphone evidence to be analyzed by the researchers. In figure 3 also listed the smartphone's IMEI number is 356578090301222 and it is also explained that the smartphone has been rooted.

\subsubsection{Maintenance}

This stage is done to maintain digital evidence to ensure authenticity. At this stage the Oxygen Forensic tool is used to determine the authenticity of the evidence, which can be seen in figure 6 . 


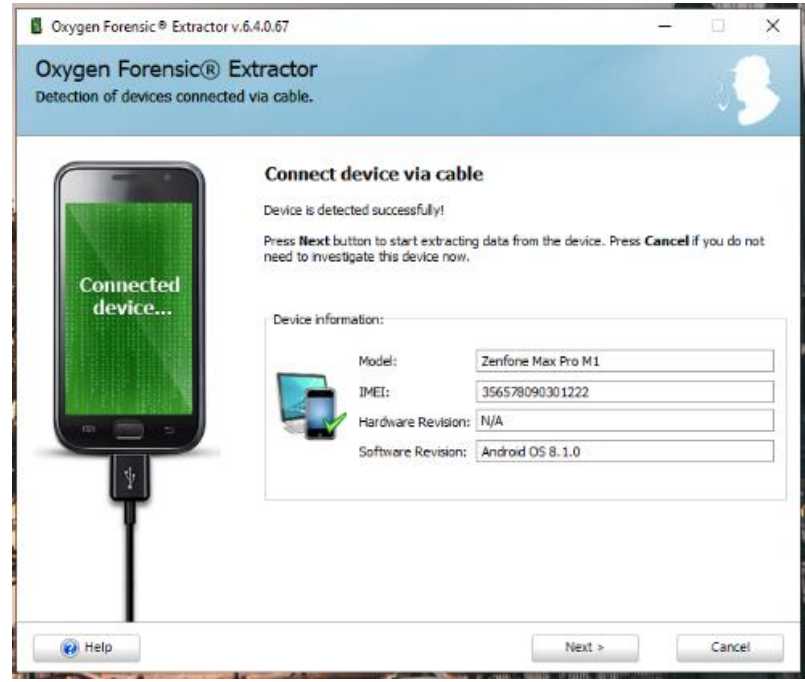

Figure 6. Authenticity of evidence with Oxygen Forensic tool

After the smartphone is connected to Forensic Oxygen, then get information about the smartphone namely Zenfone Max Pro M1 with IMEI 35657809301222 and Android OS 8.1.0

\subsubsection{Collection}

This stage is carried out the process of collecting evidence samples that are suspected to be potentially strong evidence. In the Instagram app, download the data, download the data and produce the ZIP file that can be seen in figure 7,

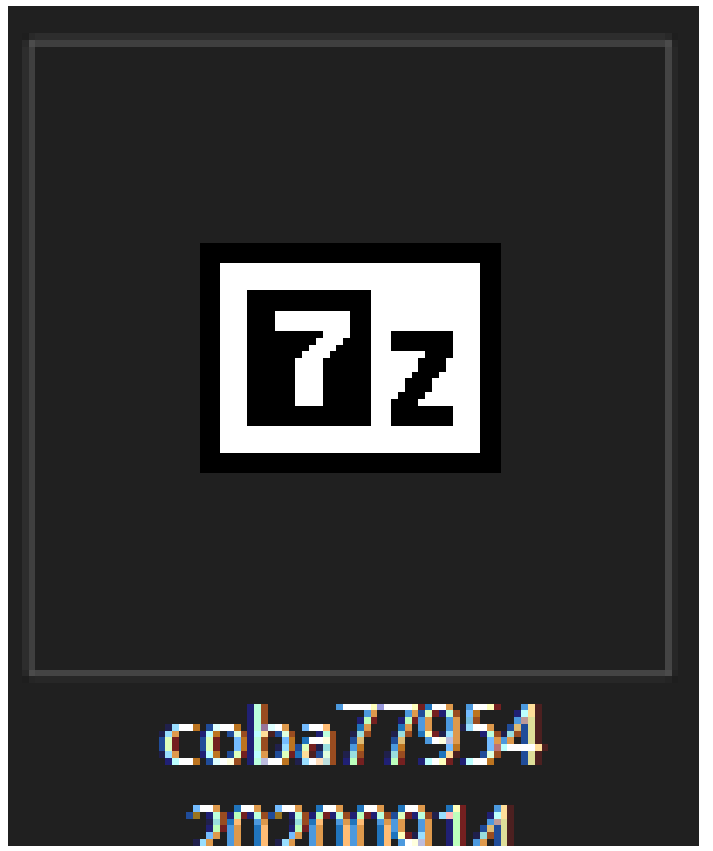

Figure 7. ZIP File Instagram

The downloaded Zip file after extracting generates 20 JSON files that can be viewed in figure 8 .

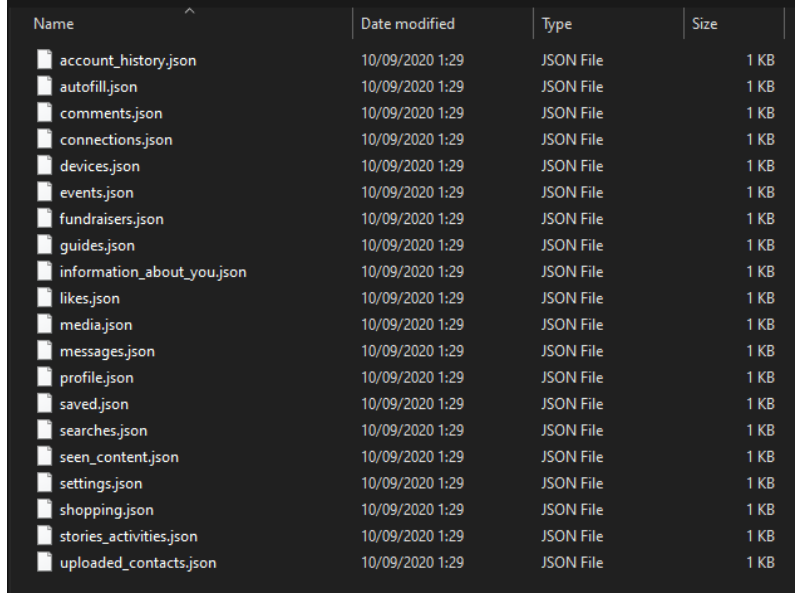

Figure 8. Json files downloaded from Instagram data

Some of the Json files will be selected and laterally instincted using the JSON Viewer tool, while with oxygen forensic tool is done extraction data that can be seen in figure 8 .

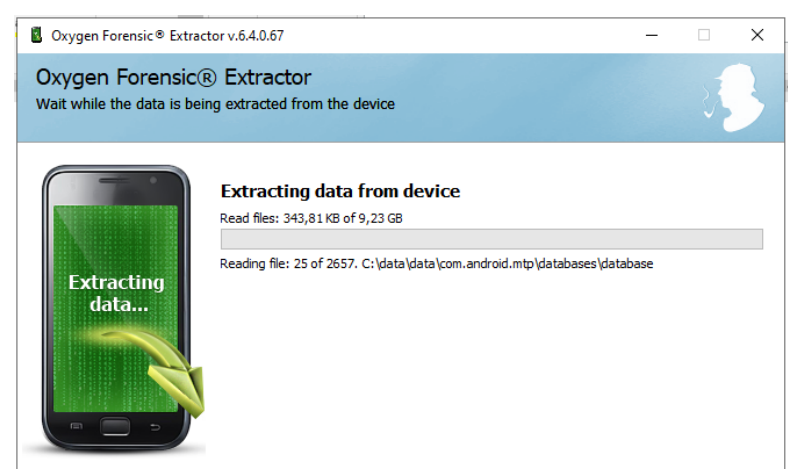

Figure 9. Data extraction process with Oxygen Forensic

From the process of extracsing data on the smartphone produces some data that can be seen in figure 10 .

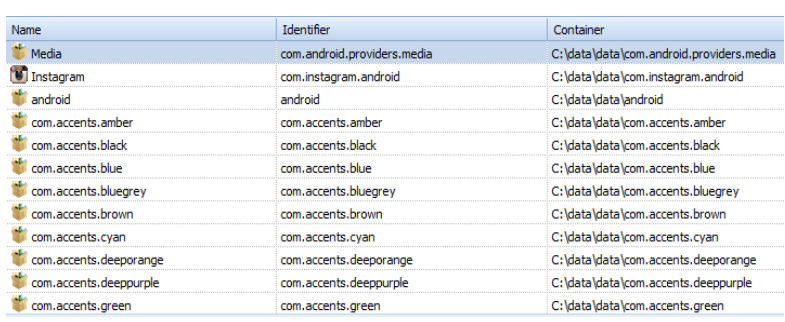

Figure 10. Data collection with Oxygen Forensics

The above image can be viewed data that will be selected to be examined at a later stage.

\subsubsection{Examination}

At this stage the data filtering that will be indexed, from some json files that have been downloaded, is retrieved json file with the name messages.json because the file contains messages on the instagram service can be seen in figure 10 . 


\begin{tabular}{|c|c|c|c|}
\hline Name & Date modified & Type & Size \\
\hline Daccount_history.json & 10/09/2020 1:29 & ISON File & $1 \mathrm{~KB}$ \\
\hline autofill.json & 10/09/2020 1:29 & ISON File & $1 \mathrm{~KB}$ \\
\hline D comments.json & 10/09/2020 1:29 & ISON File & $1 \mathrm{~KB}$ \\
\hline connections.json & 10/09/2020 1:29 & ISON File & $1 \mathrm{~KB}$ \\
\hline devices.json & 10/09/2020 1:29 & JSON File & $1 \mathrm{~KB}$ \\
\hline events.json & 10/09/2020 1:29 & ISON File & $1 \mathrm{~KB}$ \\
\hline D fundraisers.json & 10/09/2020 1:29 & ISON File & $1 \mathrm{~KB}$ \\
\hline guides.json & 10/09/2020 1:29 & ISON File & $1 \mathrm{~KB}$ \\
\hline D information_about_you.json & 10/09/2020 1:29 & ISON File & $1 \mathrm{~KB}$ \\
\hline likes.json & 10/09/2020 1:29 & ISON File & $1 \mathrm{~KB}$ \\
\hline Dmadiaisnn & $10100 / 20301.20$ & ISOM File. & $1 \mathrm{KR}$ \\
\hline messages.json & 10/09/2020 1:29 & ISON File & $1 \mathrm{~KB}$ \\
\hline E protile.json & 10/09/2U2U1:24 & JSON File & $\mathrm{TKB}$ \\
\hline Daved.json & $10 / 09 / 20201: 29$ & ISON File & $1 \mathrm{~KB}$ \\
\hline searches.json & 10/09/2020 1:29 & ISON File & $1 \mathrm{~KB}$ \\
\hline Deen_content.json & 10/09/2020 1:29 & JSON File & $1 \mathrm{~KB}$ \\
\hline Dettings.json & 10/09/2020 1:29 & JSON File & $1 \mathrm{~KB}$ \\
\hline shopping.json & 10/09/2020 1:29 & ISON File & $1 \mathrm{~KB}$ \\
\hline D stories_activities.json & 10/09/2020 1:29 & ISON File & $1 \mathrm{~KB}$ \\
\hline D uploaded_contacts.json & 10/09/2020 1:29 & ISON File & $1 \mathrm{~KB}$ \\
\hline
\end{tabular}

Figure 11. JSON File Selection

The messages.json file is later extracted with JSON Viewer, while the results of the examination with Oxygen forensic are retrieved

the

C:Idataldatalcom.instagram.androidldatabasesldirect.db file can be viewed in Figure 12 .

C:Idataldata Kcom.instagram.android lcacheltmp_photo_4210036795658394593.jpg C:Idataldata (com.instagram.android lcacheltmp_photo_7080661022919333727.jpg C:Idataldata (com.instagram.android lcacheltmp_photo_7099418528275886331.jpg C: Idata ldata lcom.instagram. android lcacheltmp_resources Vesource $301811652840 \mathrm{f}$ C: Idata ldata Kcom.instagram.android lcrash_lock

\begin{tabular}{|c|}
\hline C: |data|data (com. instagram.android|databases /direct.db \\
\hline
\end{tabular}

C: Idata |data lcom. instagram. android /databases \fileregistry.db

C:Idata |data lcom.instagram.android ldatabases |time_in_app_40736399929.db

C:Idata ldata lcom.instagram.android ldatabases \time_in_app_40736399929.db-jour C: Idata ldata Kcom.instagram. android ldatabases Itransactions. db

C: Idata |data |com.instagram.android|databases |transactions.db-shm

\section{Figure 12. Selection of data from Oxygen Forensics}

\subsubsection{Analysis}

Analysis of the results obtained using the JSON Viewer application is then filtered as necessary for the cyberbullying identification process so that in the process of identification analysis it is easier and can be seen how the details of the message are received starting from the content of the message, from whom the message was sent in Figure 13.

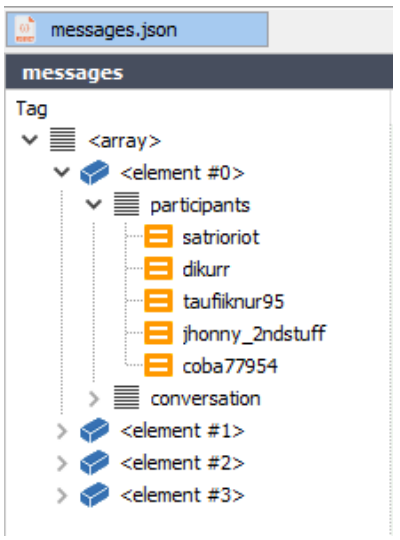

Figure 13. Who's messaging
There are 5 people involved in the conversation in instagram messaging service namely satrioriot, dikurr, taufiknur95, jhonny_2ndstuff, and coba77954. The content of the message identified as an act of cyberbullying is shown in figure 14 .

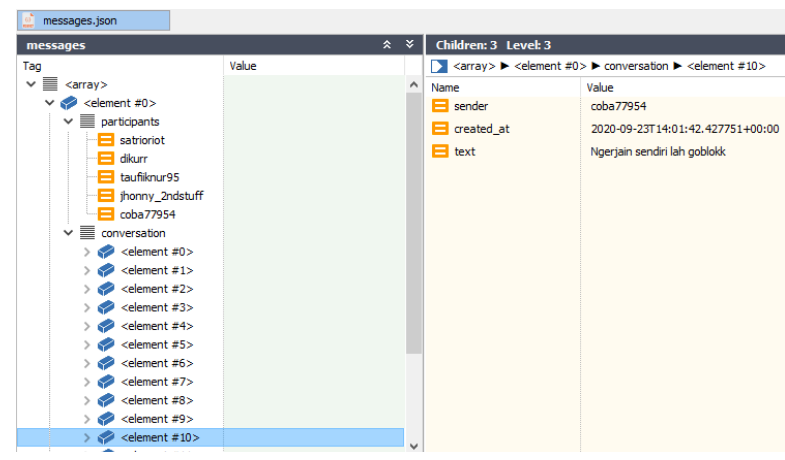

Figure 14. Content of messages identified as cyberbullying

In Figure 14. Can find out the content of the message, who sent the message and what date it was sent. Other messages containing cyberbullying elements can be seen in figure 15 .

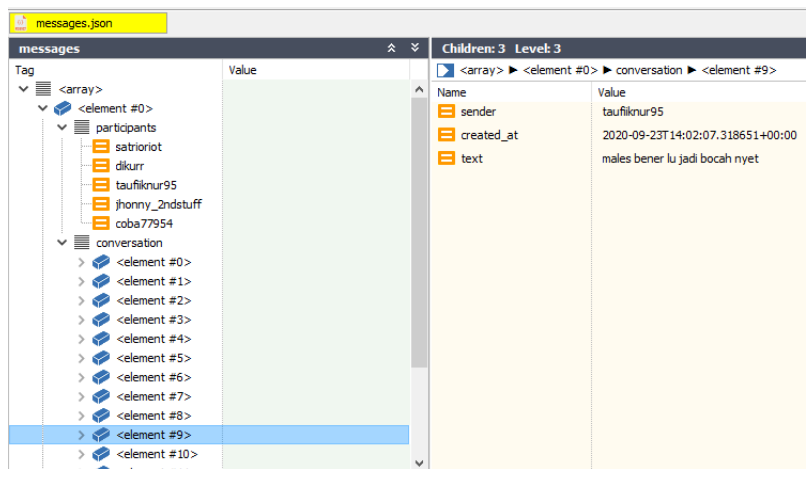

Figure 15. Content of messages identified as second cyberbullying

Furthermore, the extraction results using Oxygen forensic in the form of conversations and pictures on the Instagram messaging service, seen in figure 16.

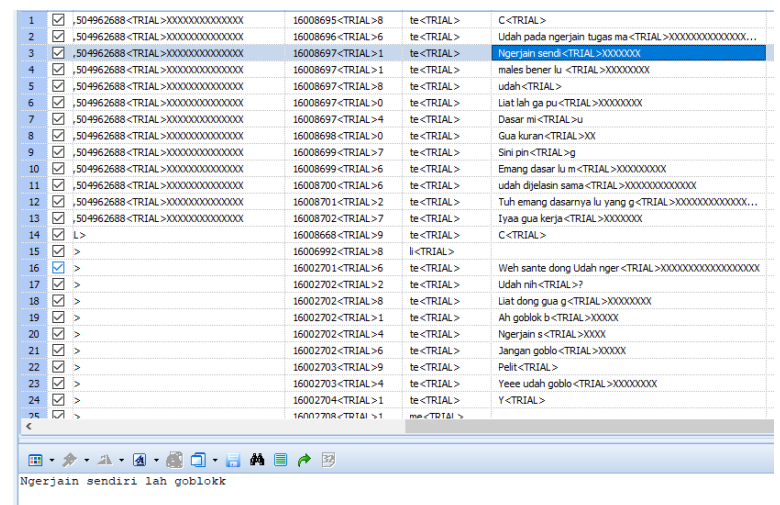

Figure 16. Extras with Oxygen Forensic

In figure 16 . can be seen conversations identified cyberbullying actions, other cyberbullying actions can be seen in figure 17. 


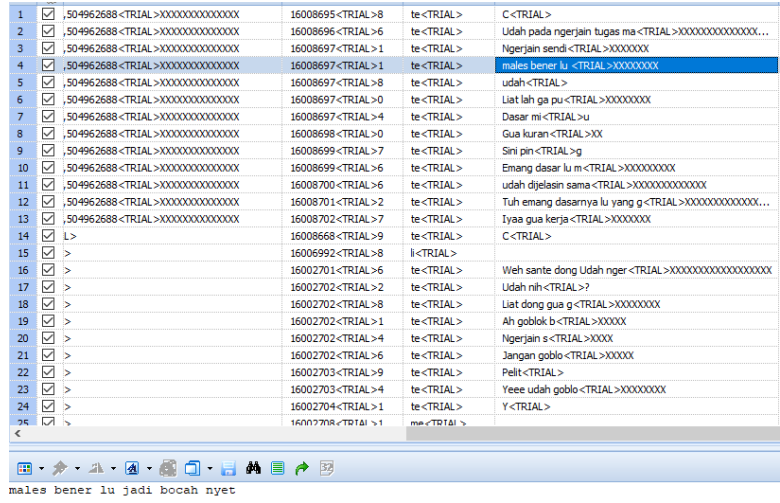

Figure 17. Extraction results using Oxygen Forensic

In addition to displaying conversation sessions on Oxygen Forensic also displays photos/images and can be seen in figure 18 .

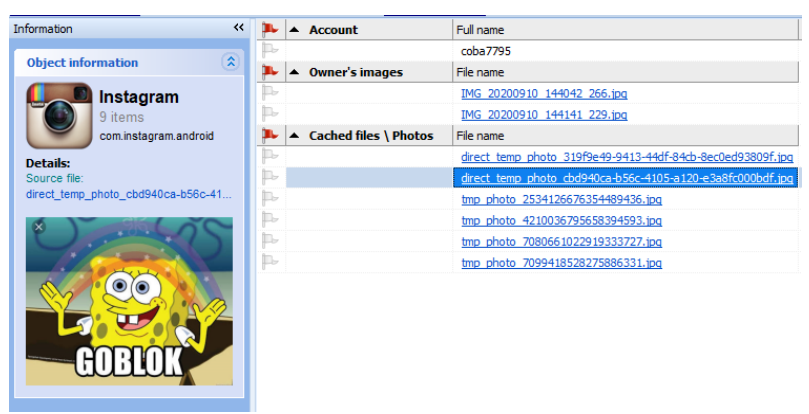

Figure 18. Fill in photos/images on instagram messaging service

\subsubsection{Presentations}

The results are obtained from the acquisition process using oxygen forensic application and JSON Viewer. The data that is successfully obtained will be digital evidence from instagram-attached smartphones. smartphones in the form of electronic evidence used and indicated cyberbullying crimes. Digital evidence obtained in the form of image/photo data and conversations/chats. From the analysis stage it can be concluded that the JSON Viewer tool can only display conversation sessions only, while Oxygen Forensic can display conversation sessions as well as images/photos. Extraction using Oxygen Forensic tool is for 3 hours from 13:09:20 to 16:13:17 and is held on September 24, 2020. The investigator of this study is Satrio Pambayun.By following several inspection procedures, the evidence is analyzed with Oxygen Forensics and JSON Viewer with their respective functions and features. So the focused results are some things related to suspects and Instagram, for more details see Table 1 .

Table 1. Results of All Methods

\begin{tabular}{|c|c|c|c|}
\hline No & $\begin{array}{c}\text { Digital } \\
\text { Evidence }\end{array}$ & $\begin{array}{c}\text { Oxygen } \\
\text { Forensics }\end{array}$ & $\begin{array}{c}\text { JSON } \\
\text { Viewer }\end{array}$ \\
\hline 1 & Photo & $\checkmark$ & - \\
\hline 2 & Video & $\checkmark$ & - \\
\hline 3 & Text & $\checkmark$ & $\checkmark$ \\
\hline 4 & User Name & $\checkmark$ & $\checkmark$ \\
\hline 5 & Link & $\checkmark$ & $\checkmark$ \\
\hline
\end{tabular}

From table 4 it can be concluded that Oxygen Forensics Application can display everything while JSON Viewer cannot display images and videos.

\section{CONCLUSION}

The application of forensic mobile messaging service instagram is used to obtain digital evidence on the messaging service Instagram. On smartphones, acquisitions are made to show conversations that are suspected of being crimes committed. With the application of mobile forensic analysis conducted, this study managed to obtain evidence in the form of data needed by researchers such as chat sessions. The use of oxygen forensic and JSON viewer for extraction on smartphones successfully extracts data stored on internal memory as well as external memory.

\section{REFERENCES}

[1] Mukti, W. A., Masruroh, S. U., \& Khairani, D. (2018). Forensic Evidence Analysis and Comparison of Facebook and Twitter Social Media Apps on Android Smartphones.Jurnal Teknik Informatika, 10(1), 73-84.

[2] Riadi, I., Yudhana, A., \& Caesar, M. (2018). Akuisisi Digital Proof On Android-Based Instagram Messenger Using National Institute of Justice (Nij). Jurnal Teknik Informatika Dan Sistem Informasi, 4(2), 219-227.

[3] Yudhana, A., Umar, R., \& Ahmadi, A. (2018). Google Drive Forensic Data Acquisition On Android With National Institute of Justice Method ( NIJ ). Jurnal CoreIT: Jurnal Hasil Penelitian Ilmu Komputer Dan Teknologi Informasi, 4(1), 8 .

[4] Faiz, M. N., Prabowo, W. A., \& Sidiq, M. F. (2018). Comparative Study of Forensic Digital Investigations into Crimes. 1(1), 47-53.

[5] Syahib, M. I., Riadi, I., \& Umar, R. (2018). Beetalk Application Digital Forensic Analysis For Handling. Seminar Nasional Informatika 2018 (SemnasIF 2018) UPN "Veteran" Yogyakarta, 24 November 2018, 2018(November), 134.

[6] Yudhana, A., Riadi, I., \& Anshori, I. (2018). Facebook Messenger Digital Proof Analysis Using Nist Method. It Journal Research and Development, 3(1), 13.

[7] Yudhana, A., Umar, R., \& Ahmadi, A. (2018). Google Drive Forensic Data Acquisition On Android With National Institute of Justice Method ( NIJ ). Jurnal CoreIT: Jurnal Hasil Penelitian Ilmu Komputer Dan Teknologi Informasi, 4(1), 8.

[8] Yadi, I. Z., \& Kunang, Y. N. (2014). Forensic analysis on the Android platform. Konferensi Nasional Ilmu Komputer (KONIK), 141-148.

[9] Riadi, I., Umar, R., \& Nasrulloh, \& I. M. (2018). Digital Forensic Analysis On Frozen Solid State Drive With National Institute of Justice Method (Nij). Elinvo (Electronics, Informatics, and Vocational Education), 3(1), 70-82.

[10] Fauzan, A., Riadi, I., \& Fadlil, A. (2017). Digital Forensic Analysis On Line Messenger For Cybercrime Handling. Annual Research Seminar (ARS), 2(1), 159163.

[11] Mukti, W. A., Masruroh, S. U., \& Khairani, D. (2018). Forensic Evidence Analysis and Comparison of Facebook and Twitter Social Media Apps on Android Smartphones. Jurnal Teknik Informatika, 10(1), 73-84.

[12] Riadi, I., Umar, R., \& Nasrulloh, \& I. M. (2018). Digital Forensic Analysis On Frozen Solid State Drive With 
National Institute of Justice Method (Nij). Elinvo (Electronics, Informatics, and Vocational Education), $3(1), 70-82$.

[13] Zakiyah, Ela Zain, Sahadi Humedi, and Meilanny Budiarto Santoso. 2017. "Factors That Affect Teens In Bullying." 4: 324-30.

[14] Riadi, I., Yudhana, A., \& Caesar, M. (2018). Akuisisi Digital Proof On Android-Based Instagram Messenger Using National Institute of Justice (Nij). Jurnal Teknik Informatika Dan Sistem Informasi, 4(2), 219-227.

[15] Ary Budi, W., Ajeng, A., Dian, T. (2017). Implementation of JSON Data to Support Application Development In Higher Education With Restfull Techniques And Web Service. Techknomedia Journal (TMJ) 2(1)

[16] Warsito, Ary Budi, Ajeng Ananda, and Dian Triyanjaya. 2017. "Implementation of JSON Data To Support Application Development In Higher Education With
Restfull Techniques And Web Service.” Technomedia Journal 2(1): 26-36.

[17] Nuril, A., Son, A., Akbar, A., (2020) Mobile Forensics Logical Extraction on Android E-Commerce App. Jurnal Mobile and Forensics (MF) 2(1), 1-10.

[18] Riadi, I., Yudhana, A., \& Caesar, M. (2018). Acquisition of Digital Evidence On Android-Based Instagram Messenger Using National Institute of Justice Method (Nij). Jurnal Teknik Informatika Dan Sistem Informasi, 4(2), 219-227.

[19] Septy Rahayu. (2012). Cyberbullying as a Negative Impact of the use of Information Technology. Journal of Informatyon System, 8.

[20] Syahib, M. I., Riadi, I., \& Umar, R. (2018). Digital Forensic Analysis Beetalk Application For Handling. National Seminar on Informatics 2018 (SemnasIF 2018) UPN "Veteran" Yogyakarta, 24 November 2018, 2018 (November), 134 